\title{
O Curso em busca de autor ${ }^{1}$
}

\author{
Jürgen Trabant
}

Universidade Livre de Berlim

\section{Resumo}

O Curso de Linguística Geral (1916/1922) é um dos livros mais importantes da história da linguística, talvezo o mais influente de todos os tempos. Ele é a origem de uma renovação e de uma reorientação das ciências humanas durante a primeira metade do século XX. Linguistica sincrônica, estruturalismo, semiologia são os termos que se ligam ao Curso. Depois de cinquenta anos de leitura e de discussões calorosas esse livro é substituido por um livro novo, o Curso de Linguística Geral de Ferdinand de Saussure (1967/1972). A conferência tentará analisar as principais operações dessa transformação e refletir sobre suas consequências.

1 Comunicação originalmente apresentada no Colloque international Le Cours de Linguistique Générale 1916-2016: Le Devenir, Paris, 15-17 junho de 2016. Tradução de Marcio Alexandre Cruz. 
1. O Curso de linguística geral, publicado em 1916 e em 1922, é um dos livros mais importantes da história da Linguística, talvez o mais influente de todos os tempos. Ele é a origem de uma renovação da Linguística e de uma reorientação das ciências humanas em meados do século XX. Em 1967, a tradução italiana é publicada: Corso di linguistica generale, traduzido e comentado por Tullio de Mauro. Não se trata aí tão somente do Curso sob outra forma linguística ou de um evento da linguística italiana, mas, cinquenta anos depois do Curso, de um evento importante para toda a linguística. Esta edição é traduzida para o francês e publicada em 1972. Ela se torna a edição padrão do Curso. Desde então, compramos o Curso na forma que lhe deu De Mauro em 1967.

2. Este é um fato admirável, talvez sem precedentes: um paratexto (introdução, nota biográfica e notas) estrangeiro de um clássico é traduzido na língua original e se torna a edição padrão desse mesmo clássico, sobretudo se considerarmos que essa edição transforma o clássico em questão e faz dele um livro radicalmente novo.

2.1. A tradução italiana demora a chegar, visto que a tradução japonesa data de 1928 e a alemã, de 1931. Os italianos não precisavam da tradução para ler o Curso. Mas eles o leram com certa reserva. A leitura - cética - de Pagliaro em 1930 me parece bastante paradigmática. Depois da Segunda Guerra Mundial, o grande linguista Terracini (1949, 1963), à procura de uma teoria para a renovação da linguística, a encontrou na tradição Humboldt-Vossler-Spitzer e não no Curso. Ele não podia aceitar as grandes exclusões do Curso: língua (e não fala), linguística interna (e não cultura), sincronia (e não diacronia), arbitrário (e não iconicidade) e ele apenas aceitava a ideia estrutural, portanto aquela de um conjunto de unidades linguísticas conectadas. Mas nos anos 1960 aumenta a presença das ideias estruturais, graças ao linguista Lepschy (1966) e graças aos estudos literários: graças a Avalle, Segre, Corti que dependem do Curso via Barthes e Greimas e que elaboram a ideia de uma semiologia estrutural.

Portanto, os grandes temas do saussurismo estão presentes, em amigos e adversários, quando é publicada a tradução italiana do Curso: Ferdinand de Saussure: Corso di linguistica generale. Introduz̧ione, traduzione e commento di Tullio de Mauro. Esse livro foi um sucesso imediato e enorme.

Mas não é a tradução, a forma linguística italiana, que faz a importância desse livro. O que faz dessa tradução italiana do Curso um evento crucial da linguística moderna é que ela dá ao Curso 
uma profundidade filológica (biografia, documentos, tradições) que o transforma radicalmente: o Curso é integrado a um texto mais extenso que ele próprio. É como se o Curso encontrasse uma casa onde morar. De Mauro reconstrói a história de Ferdinand de Saussure e do Curso em sua bela Introdução (18 páginas) e nas "Notas biográficas e críticas sobre Ferdinand de Saussure" (85 páginas). E ele acrescenta 305 notas (e uma bibliografia em 90 páginas) nas quais ele fornece explicações sobre a discussão linguística, mas, sobretudo, nas quais ele liga o texto do Curso às fontes a partir das quais ele foi escrito.

E essas duas operações mudam tudo. Elas não aumentam apenas o corpo material do livro ao envolvê-lo em vinte páginas que precedem o texto e 175 páginas - em letras miúdas! - que o sucedem. Elas mudam o sentido do livro: o Corso é um livro que tem um autor (ou que tenta encontrar um autor: o Curso in cerca d'autore, em busca de autor) e que, por causa disso, diz frequentemente outra coisa do que aquilo que encontramos no original francês. O Corso é um livro novo, um Curso transformado.

2.2. Para avaliar a profundidade dessa transformação, é preciso, primeiramente, voltar àquilo que sabemos sobre a gênese do Curso de Linguística Geral.

Sempre soubemos - e ignorávamos regiamente - que o Curso carecia de autor ou, mais exatamente, que ele não havia sido escrito por Ferdinand de Saussure. Sabíamos explicitamente desde o livro de Godel de 1957 sobre as Fontes manuscritas e o ignorávamos da mesma forma. O Curso é um livro escrito depois da morte de Ferdinand de Saussure em 1913, por dois colegas de Genebra, com base nos cadernos de anotações de estudantes que haviam frequentado os cursos de Saussure sobre a linguística geral entre 1907 e 1911. Os dois colegas, Charles Bally e Albert Sechehaye, não assistiram às aulas. Eles não são, portanto, nem mesmo ouvintes, akroatai, de um ensino acroamático. Como Saussure tinha o hábito de destruir as notas para seus cursos, não havia sequer manuscritos da mão do próprio Saussure, portanto, de primeira mão. Não tínhamos, assim, o que, numa produção literária, chamamos normalmente de fontes. Os documentos de que dispomos são de segunda mão, oriundos de um processo acroamático e fonográfico. Como Ferdinand de Saussure era um linguista mundialmente conhecido como indo-europeísta, Bally e Sechehaye queriam trazer a público as últimas ideias linguísticas, o ensino acroamático, do colega genial. Eles publicaram, por conseguinte, três anos depois da morte do grande linguista, um livro que está ligado a Ferdinand de Saussure apenas indiretamente, logo, um escrito de terceira mão. O dispositivo de escrita do livro, impresso pela primeira vez em 1916, é portanto o seguinte: 
Saussure fala (Fonte), escuta + escrita1 dos estudantes (akroatai, fonógrafos), leitura de Bally e Sechehaye dessas notas, escrita2 de Bally e Sechehaye, publicação (impressão): Curso. Esse dispositivo implica uma grande distância entre a Fonte e o produto final. Depois da produção oral, a voz, a Fonte, há quatro ou cinco outras atividades linguísticas de outras pessoas até a produção do texto. A produção textual normal se faz num só nível, ao nível da Fonte (+impressão).

Quando procuramos outro texto importante de nossa cultura com um dispositivo de produção textual igualmente complexo, devemos pensar nos Evangelhos. Os evangelhos gregos estão igualmente distantes da Fonte, do Cristo. Como Saussure, Jesus fala e não escreve, e ele não deixou anotações. Seus dizeres foram escutados, memorizados, repetidos, traduzidos em grego (esta é uma etapa a mais na produção textual, Jesus falava aramaico). Os evangelistas conhecem portanto os dizeres do Cristo de ouvido, eles escutam o que as pessoas memorizaram, traduziram, e os integram em uma narrativa escrita. Mateus, Marcos, Lucas e João não estavam presentes quando Cristo falava, eles não são akroatai diretos, do mesmo modo que Bally e Sechehaye, que não ouviram a voz de Saussure ${ }^{2}$. Bally e Sechehaye não escondem o problema de sua produção textual que essa situação criou. Mas eles são otimistas quanto ao resultado de seu "trabalho de assimilação e de reconstituição" (CLG, p. 9). Os evangelistas, quanto a eles, não duvidam do seu trabalho de assimilação e de reconstituição, não há sinal de dúvida nos Evangelhos.

Haja vista esse dispositivo de produção, vale observar que são, portanto, testemunhos extremamente problemáticos quanto à fonte que exerceram grande influência no pensamento e nas ações de seus leitores.

Ora, a gênese do livro é extraordinária e Saussure não é o autor. Porém, inicialmente, ninguém se preocupava com isso. Mas, sobretudo, como no caso dos Evangelhos, isso não tem importância. O livro saiu em 1916, depois, com leves retoques, em 1922. E é sob essa forma que o livro teve o destino que todos nós conhecemos: nós o lemos, o traduzimos, fazemos dele o livro de base de uma renovação radical da linguística, que chamamos de linguística moderna ou linguística sincrônica estrutural, em oposição à velha linguística diacrônica de tipo alemão. É sob essa forma que o celebramos ou criticamos. Hjelmslev (1963) elabora sua teoria com base nesse livro, que ele acredita aperfeiçoar na glossemática. Coseriu $(1958,1962)$ organiza sua linguística em torno de

\footnotetext{
2 Bally e Sechehaye não são, portanto, São Pedro e São Paulo, como afirma Joseph (2012), mas Mateus, Marcos,
} Lucas e João. 
uma crítica dialética desse livro. Dizíamos "como escreveu Saussure", mas finalmente Saussure nada escreveu. Mas isso não tinha a menor importância. Porque o Curso não adquiria sua credibilidade e sua força científica do fato de o professor Saussure ter dito tudo verdadeiramente ou porque as palavras do Curso saíram da boca do professor ou de sua pena, mas simplesmente pela força dos argumentos do livro.

2.3. Então, em 1967, é publicado esse novo livro na Itália: Ferdinand de Saussure: Corso di linguistica generale. De Mauro volta a ligar o Curso a Ferdinand de Saussure, a propósito de quem pouco se sabia e a quem se dava pouca atenção. De Mauro dá novamente a Ferdinand de Saussure o papel de autor do Curso de linguística geral. Ele reduz a distância entre a Fonte e o texto final. São duas operações pelas quais ele volta a ligar o Curso a Saussure.

Em primeiro lugar, as notas biográficas unem esse livro estritamente a Ferdinand de Saussure, linguista genebrino de renome mundial, indo-europeísta brilhante que, no final de sua vida, havia ministrado aulas sobre a linguística geral diante de alguns estudantes. A capa do livro italiano mostra o retrato desse autor que não escreveu esse livro e que não tinha nem mesmo a intenção de escrevê-lo. Integrar o Curso - obra mais do que póstuma - à vida de Saussure não é uma ação inocente. É uma constatação bastante forte.

Em segundo lugar, as notas de De Mauro aproximam o Curso de documentos que - não sendo da mão de Saussure - são os mais próximos da pessoa de Ferdinand de Saussure. De Mauro utiliza para seu comentário notas dos estudantes que estavam presentes nos cursos do professor, logo, testemunhos escritos de viva-voz. A edição crítica de Rudolf Engler, baseada nos cadernos dos estudantes (SAUSSURE, 1967/1974), não havia ainda sido publicada quando De Mauro preparava sua edição. Isso acontecerá no mesmo ano. Mas De Mauro teve acesso ao material de Engler, utilizando-o intensamente para o seu comentário nas 305 notas.

Contudo, essas notas que parecem aproximar o texto impresso à Fonte, na verdade, o distancia. Pois elas mostram que, em muitos pontos fundamentais, o professor não havia dito o que se lê no Curso. Uma passagem de olhos superficial na edição Engler o prova dramaticamente. As coincidências entre o texto impresso e as falas do professor não são abundantes: há poucas passagens em negrito (que nessa edição marcam tais concordâncias). 
Convém aqui precisar esse "ele não disse". Eu distingo três casos: a. o professor havia organizado suas aulas diferentemente do que se lê no Curso; b. o professor disse diferentemente ou ele disse um pouco o contrário do que se lê no Curso; c. o professor não disse nada disso, os Evangelistas simplesmente inventaram passagens do texto do Curso. Eis aqui alguns exemplos desses "não ditos":

a. composição. Na longa nota 65 sobre a distinção entre língua e fala, De Mauro observa que a composição do Curso não respeita a hierarquia nem o desenvolvimento das ideias fundamentais do professor Saussure. De Mauro nos remete às notas 1759-1765 B Engler e escreve:

[...] o C.L.G. deveria começar nas páginas 249-250 e 150-152 sobre a identidade diacrônica e sincrônica, depois, continuar com o reconhecimento do caráter arbitrário do signo e, portanto, do caráter formal da língua e, enfim, concluir, no que concerne à primeira parte, com a distinção metodológica entre a consideração de um fenômeno linguístico enquanto representação de certo valor (língua) ou como manifestação fônico-acústica ou psicológica (fala).

Essa afirmação é tão grave que ela destrói quase totalmente a conexão entre o Curso e Saussure. Nós sabemos que Saussure é um pensador extremamente sensível ao "lugar hierárquico" de suas verdades. Um livro que não respeita essa hierarquia das ideias de Saussure e que muda completamente o desenvolvimento de seu pensamento é dificilmente um livro de Saussure.

b. coisas diferentes. Há, é claro, muitos casos em que o professor disse coisas diferentes do que se lê no Curso. Observo dois casos célebres e graves.

A oposição entre língua e fala do Curso, nos diz De Mauro, deveria ser considerada no sentido de uma relação dialética. Assim, a nota 63 se inicia pela constatação um tanto grave:

"no remanejamento editorial do texto manuscrito 160B Engler retirou toda a clareza no CLG 25 da definição da língua e aqui da definição da fala".

E segue a citação do que o professor disse verdadeiramente:

A Lingua é um conjunto de convenções necessárias adotadas pelo corpo social para permitir o uso da faculdade da linguagem nos indivíduos [definição]. A faculdade da 
linguagem é um fato distinto da língua, mas que não pode se exercer sem ela. Por fala designa-se o ato do indivíduo realizando sua faculdade por meio da convenção social que é a língua [definição].

As notas 128 à 145 reconstroem uma teoria dos signos que difere bastante do que se lê no Curso. Nessas notas De Mauro faz constantemente observações como: "O novo título foi ignorado pelos editores" ( $\mathrm{n}^{\circ}$ 128), "os editores misturaram [...] a velha e a nova terminologia" ( $\left.\mathrm{n}^{\mathrm{o}} 128\right)$, “fusão de duas fontes diferentes" ( $\mathrm{n}^{\circ}$ 129). Os evangelistas, profundamente enraizados em sua tradição, não haviam compreendido o caráter radical da arbitrariedade do signo em Saussure. Eles referem a arbitrariedade à relação entre significante e significado repetindo a velha tradição aristotélica do katà synthéken do significante. Eles não levaram conta, sobretudo, o desenvolvimento do pensamento de Saussure entre o primeiro e o terceiro curso. O infeliz exemplo böf/ochs pertence ainda à primeira lição, enquanto a terceira lição dá um passo decisivo. Nesse ponto, pode-se deduzir claramente dos cadernos dos estudantes que a arbitrariedade concerne ao conjunto do pensamento-som. De Mauro cita 1122B Engler: "o laço que une o significante ao significado é radicalmente arbitrário", constata que "radicalmente" desapareceu no texto dos editores e conclui:

o laço é arbitrário radicitus, em seus fundamentos mesmos, na medida em que ele une duas entidades igualmente produzidas graças a um recorte arbitrário na substância acústica e na substância significativa ( $\left.\mathrm{n}^{\circ} 136\right)$.

De todo modo, as notas de De Mauro são plenas de observações sobre as transformações das fontes, como as seguintes:

A última frase da alínea é um exemplo de redação infeliz do autêntico pensamento saussuriano $\left(\mathrm{n}^{\mathrm{o}} 228\right)$,

A última frase da passagem é um acréscimo dos editores $\left(\mathrm{n}^{\circ} 242\right)$,

A primeira e a segunda alínea são uma costura típica criada pelos editores ( $\mathrm{n}^{\circ} 256$ ).

Dessas observações decorre que aquilo que lemos no Curso corresponde apenas parcialmente ao que dizem as Fontes. Logo: o que De Mauro chama o "autentico pensiero saussureano" não foi entregue fielmente. Va pensiero! Va autentico pensiero saussureano! 
c. acréscimos: Os casos mais evidentes do que Saussure não disse são os acréscimos dos evangelistas. E o caso mais célebre, é claro, é a última frase do Curso:

A linguística tem como único e verdadeiro objeto a língua considerada nela mesma e por ela mesma (CLG, p. 317).

Na última dessas notas ( $\mathrm{n}^{\circ}$ 305), De Mauro qualifica essa frase de "selo de uma manipulação editorial das notas saussurianas que é em parte responsável pela atitude exclusivista do estruturalismo". Porque essa frase foi lida como a essência do Curso. Os evangelistas, que a inventaram, a chamam "a ideia fundamental desse curso" (CLG, p. 317). Ela foi repetida como um grito de guerra do estruturalismo ou antes, digamos, do imanentismo estrutural. De Mauro, por outro lado, nota de maneira muito crítica que essa frase exclui:

os desequilíbrios do sistema, a dinâmica sincrônica, os condicionamentos sociais, os fenômenos evolutivos, o laço entre estes últimos e as diferentes contingências históricas, todo o fluxo de fenômenos linguísticos graças aos quais a língua é forma ( $\mathrm{n}^{\circ}$ 305).

E ele acrescenta que o conceito de língua em Saussure é um conceito aberto e dinâmico. Ele cita 427-429B Engler para mostrar essa concepção dinâmica de língua. Segundo esse documento, o professor Saussure teria dito:

Primeiramente é preciso estudar as línguas, uma diversidade de línguas. Pela observação dessas línguas, concluiremos o que é universal. Ele terá então diante de si um conjunto de abstrações: isso será a língua, em que estudaremos o que se observa nas diferentes línguas. Em terceiro lugar, ficará faltando tratar do indivíduo (nº 305).

Mais uma vez: a língua é, primeiramente, as línguas em sua diversidade, nas quais encontraremos, em segundo lugar, traços universais e dos quais estudaremos, em terceiro lugar, as manifestações individuais. A frase acrescentada "a língua considerada nela mesma e por ela mesma" não evoca tal conceito de língua. Poderíamos até mesmo dizer que a última frase do Curso exclui Ferdinand de Saussure da linguística fundada pelo Curso.

2.4. Assim, as operações editoriais fazem do Corso di linguistica generale um livro que difere profundamente do Curso: um livro com um autor, o professor Saussure, e um livro que, ao 
mesmo tempo, demonstra a distância profunda entre o texto impresso do Curso e o que o professor Saussure havia dito em suas aulas. De Mauro criou um livro com uma forte tensão interior: de um lado a Fonte (o professor e seus ouvintes, akroatal), de outro lado, o Curso não raras vezes dramaticamente distante da Fonte.

Normalmente, a filologia textual descobre as raízes e os fundamentos de um texto final. Ela mostra como das hesitações e das variações sai o formato final, que o autor quis colocar no mundo. O texto final é a Verdade ou, dito de um modo leibniziano, a noção clara e distinta, oriunda das noções ainda confusas que são como o passado desse pensamento distante. As duas, obscuridade e clareza, são autênticas.

Mas considerando a gênese do Curso, é difícil manter tal atitude eufórica diante das informações filológicas. Aqui, a filologia conduz, antes, a uma atitude agressiva (Normand), disfórica. Como o produto final não é do próprio autor, a filologia abre antes um abismo de suspeitas. Ela impõe fatalmente a questão de saber se o texto final restitui fielmente o "pensamento autêntico". Porque a verdade se encontra apenas e necessariamente nas Fontes. E nelas um pensamento flutuante, aberto, hesitante e confusa seria a verdade desse livro. E o pensamento claro e distinto do livro impresso - tragicamente - não pode ser verdadeiro, porque as clarificações e sistematizações não foram sancionadas pelo Autor.

A filologia saussuriana, portanto, diferentemente do que faz a filologia normalmente, não enraíza o Curso num pensamento confuso do qual sai sua clareza final, sua verdade. Mas ela joga o Curso, a clareza dos pensamentos desse livro, no abismo de um pensamento confuso, o único verdadeiro, autêntico, criando assim uma vertigem científica, um deslize teórico, enfim, um movimento pouco estruturalista.

3. Diante de tal situação, pode-se ter posições opostas: uma posição de conciliação ou uma posição de separação, isto é, uma posição irênica ou uma posição polêmica. A posição de Tullio de Mauro (1967) ou a de Ludwig Jäger (1975, 2012).

3.1. De Mauro, que admira o Curso, não tem nenhum interesse em mostrar a distância entre o Curso e a Fonte, pelo contrário, sua intenção é aproximar os dois, dar um pai ao filho órfão. É por essa razão que ele coloca o retrato do Pai na capa. Ele tem uma atitude totalmente irênica 
diante das transformações das Fontes por parte dos evangelistas. As tensões estão aí; certamente elas não podem ser resolvidas, mas devem ser toleradas.

Dessa atitude irênica resulta um livro que deve ser lido com certa prudência. O desenvolvimento das ideias é menos preciso, o rigor das dicotomias que se encontram no texto impresso é abrandado, as coisas menos certas (por exemplo, o signo) se dissolvem numa interrogação infinita. Uma leitura estruturalista torna-se praticamente impossível, mas também a crítica do Curso perde sua justificativa, porque Saussure - o pai - estava mais próximo das críticas do Curso do que do Curso. Uma paternidade um pouco difícil.

É aqui que De Mauro invoca outro pensamento em movimento, não sistemático, as Philosophische Untersuchungen [Investigações filosóficas] de Wittgenstein. Ele escreve no Prefácio que se trata apenas de um "álbum":

Die philosophischen Bemerkungen dieses Buches sind gleichsam eine Menge von Landschaftsskizzen, die auf diesen langen und verwickelten Fahrten entstanden sind.

As observações filosóficas desse livro são quase um conjunto de esboços de paisagem, feitas durante essas viagens longas e complicadas.

Somente: é o próprio Wittgenstein que diz isso. Saussure, quanto a ele, não tinha explicitamente a intenção de publicar um "conjunto de esboços de paisagem” ou um "álbum”.

O Corso di linguistica generale di Ferdinand de Saussure, em 1967, torna-se, desse modo, um livro pós-estruturalista. Ele inaugura praticamente a época pós-estrutural. E não é por acaso que essa edição italiana é publicada ao mesmo tempo que alguns livros tipicamente pós-estruturalistas. Umberto Eco escreve La struttura assente em 1968. O título La struttura assente se distancia do estruturalismo. E não é somente a estrutura que está ausente, mas a "semiologia" também desaparece, ela se dissolve na "semiótica". Isso não é apenas uma escolha terminológica, mas uma escolha teórica, uma transição de uma ciência linguística dos signos com o signo linguístico e a língua no centro, em direção a uma ciência filosófica do signo cujo centro é a atividade da semiose (Peirce) e não o sistema. Nesse mesmo momento, em 1967, encontramos a crítica do Curso na Gramatologia de Derrida. 
3.2. A outra atitude diante das tensões entre o Curso e suas fontes é a posição polêmica, representada por Ludwig Jäger. Não à toa encontramos na capa de seu livro sobre Saussure de 2010 uma foto de Saussure disfarçado para um baile de máscara. Ludwig Jäger, a partir de 1975, reage diferentemente diante da situação filológica. Jäger parte da evidência do fato de que o Curso é um livro que não foi escrito por Saussure, que não tem, portanto, um pai, um livro órfão. Diante das Fontes, Jäger deixa o Curso como ele é, também porque é um livro de que ele não gosta muito. O Curso para Jäger é um livro que abre uma via nefasta da linguística, o estruturalismo. É um livro neopositivista, reducionista, formalista, etc. - tudo aquilo pelo que ele não tem lá grande estima. Mas ele admira muito Ferdinand de Saussure. E quando ele encontra nos documentos disponíveis um autor que não corresponde de forma alguma com as ideias do Curso, mas que é, antes, crítico daquilo que se lê nele, ele não tem piedade com esse livro órfão, ele não sai em busca de um pai, mas deixa o Curso cruelmente órfão.

Mas ele está decidido a reencontrar "die authentische Sprach-Idee", a concepção linguística autêntica de Ferdinand de Saussure, linguista genebrino célebre, morto em 1913. E suas pesquisas o conduzem à tradição humboldtiana. Em seu primeiro livro sobre Saussure, de 1975, Jäger reconstrói um Saussure humboldtiano, representante de uma linguística hermenêutico-culturalista, em forte oposição à epistemologia neopositivista e deducionista do Curso - e que reencontramos nos fragmentos e notas de Saussure descobertos em 1996 (SAUSSURE, 2011). E como em De Mauro, o Saussure autêntico o faz pensar nas Philosophische Untersuchungen de Wittgenstein.

Mesmo se não estamos de acordo com essa interpretação "alemã" de Saussure, Jäger, com essa separação radical do Curso e Saussure, libera a discussão saussuriana da pesquisa "etimológica", complicada e não muito convincente - do Curso. E ele descobre um grande linguista. Em seu livro de 2010, que resume quarenta anos de pesquisas saussurianas, ele nos apresenta um jovem indo-europeísta genial, o Saussure do Mémoire e dos outros escritos impressos reunidos no Recueil. Esse indo-europeísta entra numa crise profunda - sobretudo depois de Paris -, crise de reflexões sobre as bases da linguística. E Jäger encontra nos cadernos dos estudantes e nos outros documentos a partir de 1890 os documentos dessa reflexão atormentada que o Curso - em sua demasiada clareza - não reflete.

Ora, essa atitude polêmica é de uma clareza convincente. Mas, no final das contas, a separação radical entre o Curso e Saussure não pode lograr. Também a reconstrução histórica de um grande linguista, Saussure, é necessariamente - tragicamente - tributária do Curso. Sem o Curso, sem o 
aparecimento desse livro na cena da linguística internacional, sem a revolução proveniente desse livro, Jäger não teria jamais se dedicado a Ferdinand de Saussure - que tem sem dúvida seu lugar na história dos estudos indo-europeístas, mas cujas reflexões sobre as bases da linguística não teria certamente encontrado o interesse de Jäger se elas não fossem transformadas, travestidas, traídas pelo Curso de Linguística Geral.

\section{Referências}

COSERIU, Eugenio. Sincronia, diacronia e historia: el problema del cambio lingüístico. Montevideo: Universidade de La Republica, 1958.

Teoría del lenguaje y lingüística general. Madrid: Gredos, 1962.

DERRIDA, Jacques. De la grammatologie. Paris: Minuit, 1967.

ECO, Umberto. La struttura assente. Milano: Bompiani, 1968.

GODEL, Robert. Les Sources manuscrites du "Cours de linguistique générale" de F. de Saussure. Genève: Droz, 1957.

HJELMSLEV, Louis. Prolegomena to a Theory of Language. Madison: The University of Wisconsin Press, 1963 [1943].

JÄGER, Ludwig. Zu einer historischen Rekonstruktion der authentischen Sprach-Idee F. de Saussures. Thèse Düsseldorf, 1975.

Ferdinand de Saussure zur Einführung. Hamburg: Junius, 2010.

JOSEPH, John E. Saussure. Oxford: Oxford University Press, 2012.

LEPSCHY, Giulio. La linguistica strutturale. Torino: Einaudi, 1966.

NORMAND, Claudine. Saussure. Paris: Les Belles Lettres, 2000.

PAGLIARO, Antonino. Sommario di linguistica arioeuropea. Palermo: Novecento, 1993 [1930].

SAUSSURE, Ferdinand de. Cours de linguistique générale. Publié par Charles Bally et Albert Sechehaye. Paris: Payot, 1962 [1916/22].

Grundfragen der allgemeinen Sprachwissenschaft. Übers. Herman Lommel. Berlim: de Gruyter, 1931. 
Corso di linguistica generale. Introduzione, traduzione e commento di Tullio De Mauro. Bari: Laterza, 1970 [1967].

Cours de linguistique générale. Ed. critique par Rudolf Engler. 2 tomes. Wiesbaden: Harrassowitz, 1967/74.

Cours de linguistique générale. Édition critique préparée par Tullio De Mauro. Paris: Payot, 1972.

Science du langage. De la double essence du langage. Édition des Écrits de linguistique générale établie par René Amacker. Genève: Droz, 2011.

TERRACINI, Benvenuto. Guida allo studio della linguistica storica. I. Profilo storico-critico. Roma: Edizioni dell'Ateneo, 1949.

Lingua libera e libertà linguistica. Introduzione alla linguistica storica. Torino: Einaudi, 1970 [1963].

TRABANT, Jürgen. Faut-il défendre Saussure contre ses amateurs? Notes item sur l'étymologie saussurienne. Langages, v. 159, p. 111-124, 2005.

Saussure contre le Cours. In: RASTIER, François (Org.). De l'essence double du langage et le renouveau du saussurisme. Paris: Lambert-Lucas, 2016, p. 173-182.

WITTGENSTEIN, Ludwig. Philosophische Untersuchungen. Frankfurt am Main: Suhrkamp, 1971 [1953]. 